\title{
Scientific Articles and Patent Applications on Biodiesel Production from Lignocellulosic Biomass
}

\author{
Edgar Gutiérrez Infante ${ }^{1 *}$, Argimiro Resende Secchi², Luis Fernando Leite ${ }^{3}$, \\ Adelaide Maria de Souza Antunes ${ }^{3,4}$
}

\author{
${ }^{1}$ Programa de Doutorado em Engenharia de Processos Químicos e Bioquímicos, Universidade Federal do Rio de Janeiro, \\ Rio de Janeiro, Brazil \\ ${ }^{2}$ Instituto Alberto Luiz Coimbra de Pós-Graduação e Pesquisa de Engenharia, Universidade Federal do Rio de Janeiro, \\ Rio de Janeiro, Brazil \\ ${ }^{3}$ Escola de Química, Centro de Tecnologia, Universidade Federal do Rio de Janeiro, Rio de Janeiro, Brazil \\ ${ }^{4}$ Instituto Nacional da Propriedade Industrial INPI, Rio de Janeiro, Brazil \\ Email: *edgargi@hotmail.com
}

How to cite this paper: Infante, E.G., Secchi, A.R., Leite, L.F. and de Souza Antunes, A.M. (2021) Scientific Articles and Patent Applications on Biodiesel Production from Lignocellulosic Biomass. Journal of Environmental Protection, 12, 371-390. https://doi.org/10.4236/jep.2021.126023

Received: April 11, 2021

Accepted: June 12, 2021

Published: June 15, 2021

Copyright (c) 2021 by author(s) and Scientific Research Publishing Inc. This work is licensed under the Creative Commons Attribution International License (CC BY 4.0).

http://creativecommons.org/licenses/by/4.0/

\section{Open Access}

\begin{abstract}
This document was conducted to identify trends in research activity (published articles) and technology (patent applications) on the production of biodiesel from lignocellulosic biomass. The Web of Science, Compendex, and Scopus databases were used to retrieve articles and Derwent Innovation was used to search for patent applications; 300 articles and 169 patent applications were retrieved. The most common research goals (microbial lipid production, acid pretreatment, and pyrolysis) were identified from an analysis of the author's keywords. The countries most involved in research are China (96 articles), United States (68), and India (19). The top countries in international partnerships research were United States (22), China (16), and Germany (11). Bioresource Technology (54), Biotechnology for Biofuels (18), and Green Chemistry (13) are the journals with the most published articles. United States (84) is the leader on patent applications, followed by China (15) and Japan (5).
\end{abstract}

\section{Keywords}

Biodiesel, Lignocellulosic Biomass, Research Articles, Patent Applications

\section{Introduction}

Many countries around the world are concerned about the preservation of the 
environment, which generates a growing interest in seeking new sources of alternative and sustainable energy [1]. The increasing emissions of greenhouse gases and pollutants from the burning of fossil fuels are exacerbating air pollution levels and global warming. These effects make biofuels more interesting [2]. The main components of the cost of biodiesel are the raw materials, which account for $70 \%$ to $95 \%$ of total production costs [3]. The low cost of raw materials is the principal concern, together with the improvement of the efficiency of the production process and the development of low-cost catalysts [4] [5]. One of the best sources of biofuels is lignocellulose, which is the most abundant and widely available form of biomass in the plant [6]. However, lignocellulose is a complex resource that has to be transformed into simpler molecules that can then be transformed into biofuels and chemicals [7]. Although the conversion of lignocellulosic biomass into ethanol has been successfully achieved, there is still a major obstacle to its use, namely, the scarcity of economically viable technologies for its conversion into biodiesel [8]. Lignocellulosic biomass is found in agricultural and forest waste [9], the first step for its conversion into biofuel via biochemical processes is pretreatment, which separates out its different components. Progress made in lignocellulosic biomass pretreatment and conversion present promising opportunities for harnessing the economic potential of different lignocellulosic wastes [10].

The last decade was marked by significant advances in research into multiple aspects of lignocellulosic biodiesel, including different pretreatment methods, [11] [12] different microbiological conversion methods [13] [14] and different physicochemical conversion methods [15] [16] [17]. These studies have been published in a variety of journals, however, no systematic analysis of the research into processes on lignocellulosic biodiesel production has been conducted to date [18]. Bibliometric is a set of methods that uses quantitative and statistical analysis to study the distribution of information from documents and how it interconnects [19]. This set of effective research tools has been widely used for compiling statistics on scientific output and research trends in several science and engineering disciplines [20]. The objective of this paper was to evaluate the global panorama of research and potential innovation, in technologies for the production of lignocellulosic biodiesel, based on a bibliometric survey and analysis of scientific articles and patent applications. This analysis provides useful information on hot topics about technology development and research processes by country, the most prolific patent applicants and researchers, and the top countries in research and technology development. The most common targets of the research and technological innovation were: acid and dilute acid hydrolysis in biomass pretreatment processes; fast and catalytic pyrolysis, microbial lipid production in conversion to biodiesel from lignocellulosic biomass; yeast was the most used microorganism in microbial lipid production; corn, rice and sugarcane were the agriculture residues more used as lignocellulosic biomass. All of these research purposes were identified from an analysis of the author's key- 
words of the articles and patent applications.

\section{Method}

In this study, "biodiesel" or "diesel" was used in combination with "lignocellulosic" or "lignocellulose" as a search phrase that was used to search for titles, abstracts and keywords, to search for scientific articles, from the Web of Science, Scopus and Compendex databases. Patent applications were searched in the Derwent World Patents Index (DWPI), using the manual codes H06-B04A, Q51-D03 and X22-A20C, these codes come from a curated Derwent database and were applicable to the word "biodiesel". Scientific articles and patent applications were searched in June 2020, documents were published between 1993 and 2019.

Articles and patent applications were considered relevant to our study, if the research or application focused on the use of lignocellulosic biomass for biodiesel production, as a consequence 300 relevant scientific articles and 169 relevant patent applications were obtained. These documents were analyzed and classified according to the country, institute, journal, and author-inventor keyword; then they were introduced in a database prepared for scientific articles and other for patent applications, using Microsoft ${ }^{\oplus}$ Office Excel. Network collaboration analysis was used to examine the collaborative relationships among the most productive countries and institutions [21].

\section{Results}

\subsection{Scientific Articles on the Production of Biodiesel from Lignocellulosic Biomass}

Research on the production of biodiesel from lignocellulosic biomass started in 2007, Figure 1 shows the number of articles published per year, on biodiesel production from lignocellulosic biomass (production of lignocellulosic biodiesel), compared to the number of articles on first-generation biodiesel production (biodiesel produced from feedstock like grains and seed oils), from 1993 to 2019. Articles on first-generation biodiesel production used the word "biodiesel", and they were retrieved from the Web of Science database. The Articles on lignocellulosic biodiesel production were taken from the Scopus, Compendex, and Web of Science databases. The first publication on first-generation biodiesel dates from 1993; 14 years the first publications on lignocellulosic biodiesel come out.

There was a significant increase in the publication of articles on first-generation biodiesel production in the 2000s, showing great progress particularly in the development of biodiesel technology and the economic sustainability of small and large biodiesel production plants [22]. This growth coincided with a marked increase in oil and diesel prices, which boosted the competitiveness of biodiesel industry. Biofuels are the renewable energy sources most closely linked to the price of oil; other renewable energy sources, such as wind, geothermal, and solar, are less sensitive to this factor [23] [24]. The production of articles on lignocel 


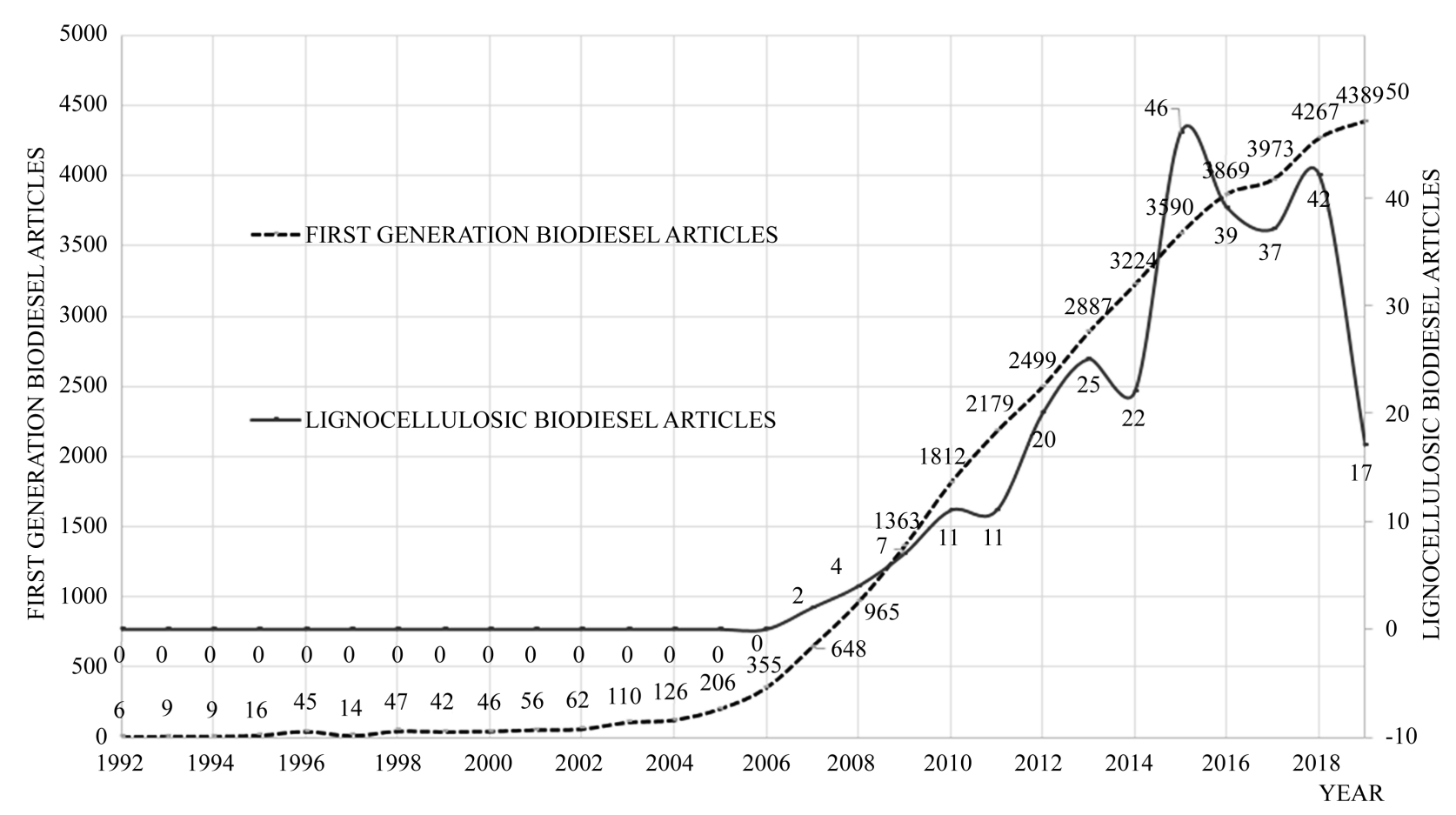

Figure 1. Publications per year of research on first-generation biodiesel and lignocellulosic biodiesel, from 1993-2019.

lulosic biodiesel has fluctuated in recent years in response to investment policies, which directly affect the publication of articles. Global pressures due to environmental problems have led some governments to stimulate grater production capacity, establishing minimum levels of biodiesel in diesel-biodiesel blends [25] [26]. There is also competition from other renewables, like wind and solar power, which also receive government incentives and have been the focus of attention in recent years, leaving biofuels in the second line [1] [27]. Another key factor is the conflict of interests between the regulatory state and agro-industry, which is marked by some specific institutional and economic conditions and can lead to favorable or unfavorable scenarios, depending on the circumstances [28].

\subsection{Leading Countries by Scientific Articles Published}

The contribution of research by countries and by entities, can be estimated according to the corresponding address of the author. Table 1 shows the production of scientific articles by country and region. Asia was the continent with the highest production of articles, almost doubled the production of America. China was the largest publisher of scientific articles, according to the International Energy Agency, energy consumption in China has increased considerably due to rapid economic expansion, [29] resulting in a marked increase in demand for oil imports, [30] in response, China established an ambitious biodiesel research goals as part of the renewable energy initiative [31]. USA is the world's leading producer of first-generation biodiesel in the world, however it is the second researcher on lignocellulosic biodiesel. Third with 17 articles is India, a country that has made significant investments in renewable energies in recent years, driven 
Table 1. Publication of scientific articles on lignocellulosic biodiesel per country and region.

\begin{tabular}{cl}
\hline \multicolumn{1}{c}{ Continents } & \multicolumn{1}{c}{ Countries } \\
\hline Asia (153) $51.0 \%$ & $\begin{array}{l}\text { China (96), India (19), Japan (10), Thailand (9), Taiwan (China) (4), } \\
\text { South Korea (4), Malaysia (3), Iran (2), Turkey (2), Indonesia (1), } \\
\text { Russia (1), Oman (1) and Pakistan (1). }\end{array}$ \\
Americas (85) $28.3 \%$ & USA (68), Canadá (7), Brazil (7), Argentina (2), and Cuba (1) \\
Europe (53) $17.7 \%$ & $\begin{array}{l}\text { Italy (8), Sweden (7), France (6), Greece (5), Spain (5), Germany (4), Austria (3), Finland (3), Netherlands (2), Belgium (2), } \\
\text { Denmark (1), Portugal (1), Slovakia (1), and Lithuania (1), Croatia (1). }\end{array}$ \\
Africa (5) $1.6 \%$ & Tunisia (3), Egypt (1),and Nigeria (1) \\
Oceania (4) $1.3 \%$ & Australia (4)
\end{tabular}

by economic progress, growth in domestic consumption and increased demand for energy, especially in the transport sector [32]. According to the World Economic Forum, China, USA and India, will drive the global expansion of renewables [33]. Publication of articles in Europe is more evenly distributed between the countries, while western European countries are more productive. Finally, in Africa and Oceania only three articles were published each. Members of the Group of Seven, or G7 (Canada, France, Germany, Italy, Japan, UK, and USA), are among the 15 top publishers of articles, accounting for $36.84 \%$. This is probably a consequence of earliest studies of first-generation biodiesel carried out in these more advanced economies, which yielded the most significant developments [34].

\subsection{Research Network}

International collaboration is important for research and innovation in renewable energies, because it can lead to higher-quality inventions at a lower cost, as resources and investments are shared and, according to recent evidence, the inventions are generated at a faster pace [35] [36]. The International Energy Agency recommends expanding international collaborative energy R \& D efforts to reduce costs and improve investment efficiency [37]. Figure 2 shows the cross-border cooperation in research into lignocellulosic biodiesel production. The size of the circle for each country is an approximate representation of the number of articles published, each line represents one article published per association.

Countries with technological affinities tend to collaborate [36], so the distribution of the collaboration network indicates the position of technological capacity of each country compare to others. Forty international partnerships on lignocellulosic biodiesel research account for 15\%, top collaborators countries are USA, Germany, and China, which is similar to the international collaboration pattern observed in research on solar and wind energy research, between USA, China, and the European Union [1]. In the lower right corner of Figure 2, there is also an isolated group of collaborators: Ireland, Greece, and Norway. 


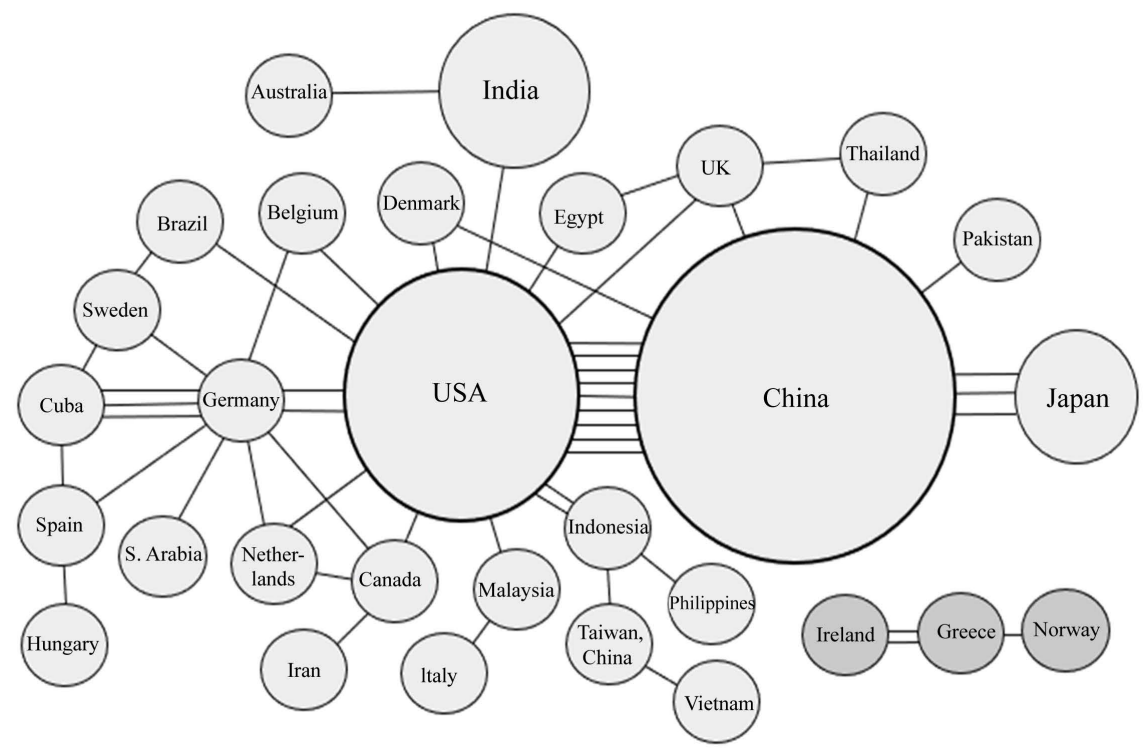

Figure 2. Collaboration network of partnerships between countries/regions, on lignocellulosic biodiesel research. Source: Based on data from the Web of Science, Compendex, and Scopus databases, from 1993-2019.

China-USA is the most prolific collaboration, resulting in nine articles. The world's leading investors in energy research and with similar technological potential, also tend to collaborate in other fields of science [1] [38]; four out of nine collaborations China-USA were between universities, three were between a university and a research institute, and two were between enterprises. Six partnerships focus on conversion methods using lipid-producing microorganisms. USA is in the middle of the research collaborations network with 22 collaborations, followed by China (16), and Germany (11). India, the third researcher country, has been involved in only two international partnerships; France, with six articles, has not collaborated internationally. Top researcher countries on firstgeneration biodiesel, are USA, China and Brazil, however, Brazil falls to tenth place in research on lignocellulosic biodiesel production. Similarly, Brazil worked in multiple international cooperation initiatives on first-generation biodiesel, but has only partnered with the USA and Sweden in research on lignocellulosic biodiesel [39]. The primary interest of US-China partnerships research on lignocellulosic biodiesel production was the study of lipid-producing microorganisms, with 6 out of 9 collaborations [40]-[45].

\subsection{Scientific Articles per Type of Entity}

Figure 3 shows the top 10 research countries on lignocellulosic biodiesel, which together represent 212 articles (80\%). Research on the production of lignocellulosic biodiesel, resulted in 260 articles, the universities are responsible for most of the publications (205) and then the institutes (49), only six articles were produced by enterprises. China is the main research country, considering universities and institutions, the Dalian Institute of Chemical Physics (DICP) is the main publisher with 12 articles, followed by the South China University of Technology 


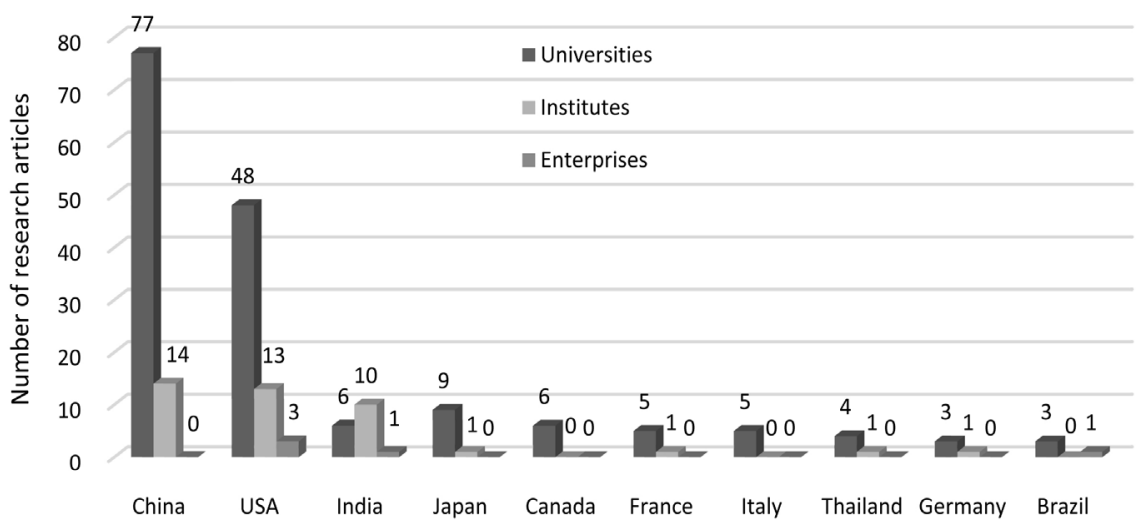

Figure 3. Top ten research countries on lignocellulosic biodiesel production.

with 11. The DICP focuses on sustainable energy research, environmental optimization, biotechnology, and advanced materials. Zongbao Zhao and collaborators from the DICP are the author of 6 publications, their research focuses on the biotransformation of lignocellulosic biomass into microbial oil and other fine chemicals. Also from DICP, Tao Zhang and collaborators with 4 articles, focuses on the use of catalysts. Minhua Zong and collaborators with 5 publications and Hong $\mathrm{Wu}$ and collaborators with 4, from the South China University of Technology, have studied lipid-producing microorganisms. Huazhong Agricultural University and Tsinghua University are other productive universities in China, with 5 publications each.

USA is the second most important research country by universities and institutions (64 articles), the Massachusetts Institute of Technology (MIT), the University of California, Berkeley, and Washington State University published 6 articles each. Shulin Chen and collaborators from Washington State University, are the author of 5 articles, their research is oriented to the study of lipid-producing microorganisms, and to the study of enzymes from the digestive system of termites [46]. Anthony Sinskey and collaborators from MIT, focusing on the genetic modification of bacteria to produce fatty acids, used Rhodococcus opacus. Wei Liao and collaborators from Michigan State University have studied integrated systems for the effective use of municipal and agricultural waste.

\subsection{Most Cited Articles}

Articles with a high number of citations tend to indicate new frontiers in their specific field [47]. Table 2 shows the ten most cited articles, five of them are related to the microbial lipid production, indicating that this conversion method is the most interesting in the scientific community. "Microbial production of fatty-acid-derived fuels and chemicals from plant biomass," by Jay Keasling from the University of California Berkeley, is the most cited article. Published in 2010 in Nature, it discusses the production of fatty esters by modified Escherichia coli [48]. Biofuels with linear hydrocarbon chains have been found to freeze more easily at low temperatures [49], the Keasling Lab is working on the production of 
Table 2. Most cited scientific articles on lignocellulosic biodiesel production.

\begin{tabular}{|c|c|c|c|}
\hline Citations & Reference & Objective & Country \\
\hline 902 & Keasling et al. 2010 [48] & Lipid-producing microorganisms & USA \\
\hline 604 & Onda et al. 2008 [51] & Hydrolysis of cellulose & Japan \\
\hline 590 & Zhao et al. 2007 [53] & Lipid-producing microorganisms & China \\
\hline 573 & Harris et al. 2010 [58] & Hydrolysis of cellulose & USA \\
\hline 520 & Steinbuchel, 2006 [59] & Lipid-producing microorganisms & Germany \\
\hline 518 & Heeres et al. 2009 [60] & Pyrolysis & Netherlands \\
\hline 451 & Murzin et al. 2008 [61] & Pyrolysis & Finland \\
\hline 364 & Chen et al. 2011 [62] & Lipid-producing microorganisms & USA \\
\hline 245 & Zong et al. 2009 [63] & Lipid-producing microorganisms & China \\
\hline 239 & Corma et al. 2011 [64] & Production of furanic compounds & Spain \\
\hline
\end{tabular}

Source: Based on data from the Web of Science. Number of citations as reported in June 2020.

more branched and cyclic hydrocarbons, using a modified Escherichia coli and Saccharomyces cerevisiae [50].

The second most cited article is "Selective hydrolysis of cellulose into glucose over solid acid catalysts," by Onda, et al. (2008) at Kochi University, Japan. Published in Green Chemistry, it focuses on the hydrolysis of cellulose [51]. Onda et al. (2009) also studied on the acid hydrolysis of glucose under hydrothermal conditions, this study ranks 24th in number of citations, with 122 in total [52]. The third most cited article, is "High-density cultivation of oleaginous yeast Rhodosporidium toruloides Y4 in fed-batch culture," by Zhao, et al. (2007), from Dalian University of Technology [53]. Zhao and collaborators wrote two highly cited articles, in position 18 with 152 citations, a research on the effects of some byproducts generated the hydrolysis of lignocellulosic biomass on fermentation with Rhodosporidium toruloides Y4 [54], and in position 19 with 141 citations, an article on medium optimization for the co-fermentation of glucose and xylose with Lipomyces starkeyi [55].

Three hundred scientific articles on the production of lignocellulosic biodiesel, were published in 97 different journals. Table 3 shows the journals with more articles published on lignocellulosic biodiesel production, the top five journals together represent $38 \%$ of all the articles. The first leading journal Bioresource technology, covers all areas relating to the treatment of biological waste, biomass, bioenergy, biotransformation, and technologies associated with conversion or production.

Biotechnology for Biofuels, the second top publisher, addresses renewable feedstocks and technological and operational progress in biofuel production. It also covers the economic, environmental, and institutional considerations relating to biofuel production. Finally, Green Chemistry, focuses on the environmental impact of chemicals and fuels, and the development of alternatives and sustainable technologies that are not toxic to living beings and the environment. 
Table 3. Most important journals on lignocellulosic biodiesel publications.

\begin{tabular}{ccc}
\hline Articles & Name of Journal & Impact Factor \\
\hline 54 & BIORESOURCE TECHNOLOGY & 7.539 \\
21 & BIOTECHNOLOGY FOR BIOFUELS & 5.096 \\
13 & GREEN CHEMISTRY & 9.480 \\
11 & ENERGY \& FUELS & 3.421 \\
10 & BIOMASS \& BIOENERGY & 3,975 \\
9 & CHEMSUSCHEM & 7.962 \\
9 & FUEL & 5.578 \\
8 & APPLIED BIOCHEMISTRY AND BIOTECHNOL. & 1,638 \\
7 & RSC ADVANCES & 3,267 \\
\hline
\end{tabular}

Source: Based on data from the Web of Science, Compendex, and Scopus databases. Impact factor according to the Journal Citation Reports, 2019.

The journals with the highest impact factors are Nature (1 article), whose impact factor is 42.778 (2019 Journal Citation Reports), and Energy \& Environmental Science (4 articles), with an impact factor of 30,289 (2019 Journal Citation Reports).

\subsection{Author Keyword Analysis}

Researchers often choose a few keywords to highlight the central idea of each publication. Author keywords have recently been used to analyze trends and identify key research points [56]. Here, we analyze keywords and publication titles to find critical aspects of the studies. Table 4 shows the 20 keywords most commonly selected by the authors of articles on lignocellulosic biodiesel production. The first keyword, "biodiesel" was the most used and some frequent combinations were "biodiesel production" and "biodiesel fuel". In contrast, the keywords "synthetic diesel" and "renewable diesel" appear relatively infrequently. The second most common keyword was "biomass", it had a lot of combinations like "lignocellulosic biomass", "biomass conversion", "biomass hydrolyzate", "biomass pretreatment", "biomass pyrolysis" and "biomass-derived". The term "lignocellulosic", can be combined with other keywords such as "lignocellulosic hydrolysate", "lignocellulosic material", and "lignocellulosic sugar", these terms are frequently used in biomass pretreatment. The fifth keyword "hydrolyzate" indicates that the most widely used pretreatment for lignocellulosic biomass is hydrolysis. The tenth keyword "pretreatment" appears with many combinations, as a result of the variety of pretreatments such as "acid pretreatment", "alkaline pretreatment", "enzymatic pretreatment" and "thermochemical pretreatment".

The seventh keyword "microbial", indicates that the most widely used technique for converting lignocellulosic biomass into biodiesel is microbial lipid production. The 12th keyword "pyrolysis" have been examined last decade in different forms of pyrolysis, such as catalytic pyrolysis and fast pyrolysis. The 8th 
Table 4. Twenty author keywords most commonly used in scientific articles.

\begin{tabular}{|c|c|c|}
\hline Author Keyword & Quantity & Most frequent combinations with other words \\
\hline Biodiesel & 87 & B. production, B. fuel, B. feedstock, II-generation B. \\
\hline Biomass & 79 & Lignocellulosic B., B. conversion, B. hydrolyzate. \\
\hline Lignocellulosic & 72 & L. Biomass, L. Hydrolyzate, L. material, L. sugar. \\
\hline Lipid & 67 & Microbial L., L. production, yeast L., L. accumulation \\
\hline Hydrolyzate & 65 & Lignocellulosic H., Biomass H., Cellulose H. \\
\hline Oil & 56 & Microbial O., Bio-oil, O. production, Single Cell O. \\
\hline Microbial & 47 & M. lipid, M. oil, M. conversion, M. activity. \\
\hline Yeast & 35 & Oleaginous Y., Y. lipid, Y. fermentation, Y. biodiesel \\
\hline Fermentation & 30 & Co-fermentation, Solid state F., lipid F., Fungal F. \\
\hline Pretreatment & 26 & Diluet-acid P., acid P., alkaline P., Thermochemical P. \\
\hline Corn & 26 & C. stover hydrolizate, Corncob residues, C. fiber. \\
\hline Pyrolysis & 24 & Fast P., catalytic P., P. oil, Co-pyrolysis. \\
\hline Cryptococcus & 18 & C. curvatus, C. albidus, C. humicola, C. psychrotolerans. \\
\hline Trichosporon & 18 & T. fermentans, $T$. cutaneum, $T$. dermatis, $T$. oleaginosus. \\
\hline Rice & 16 & R. straw, R. bran, R. husk, R. hulls. \\
\hline Bagasse & 15 & Sugarcane B., sorghum B., B. Hydrolyzate, grape B. \\
\hline Rhodosporidium & 13 & R. turoliodes, $R$. azorium. \\
\hline Straw & 13 & Rice S., wheat S., canola S. \\
\hline Rhodococcus & 12 & R. opacus. \\
\hline Rhodotorula & 11 & R. glutinis, $R$. graminis, $R$. oligophaga, $R$. mucilaginous. \\
\hline
\end{tabular}

Source: Based on data from the Web of Science, Compendex, and Scopus databases.

keyword "yeast" suggests that this microorganism is the most used for the conversion of lignocellulosic biomass, the specific yeasts mentioned are: "Cryptococcus" in position 13, "Trichosporon" in position 14, "Thodosporidium" in position 17, and "Rhodotorula" in position 20. The bacterium "Rhodococcus" appears in position 19. The lignocellulosic biomasses most used are "corn" in position 11, and "rice" in position 15. Other keywords used were "bagasse" in position 16, which is frequently combined with "sugarcane" and "sorghum". "Straw" at position 18 is another common keyword, specifically used "rice straw", "wheat straw" and "canola straw".

\subsection{Patent Applications on the Production of Lignocellulosic Biodiesel}

To identify patent applications, the Derwent Innovation database was used, which provides access to most of the world's patent offices. The patent applications were taken from the DWPI Manual codes: H06-B04A (biodiesel compounds), Q51-D03 (diesel compounds), and X22-A20C (diesel compounds), these codes were the result of searching with the world "biodiesel". These codes 
were combined with the keywords "lignocellulosic", "lignocellulose", "cellulosic" and "cellulose". This search produced 563 patent applications, after reading the abstracts were retrieved 169 relevant patent applications, i.e. patent applications focus on the production of biodiesel from lignocellulosic biomass. The search was done in June 2020, so any patent document on lignocellulosic biodiesel production processes added to the database after this date were not retrieved here.

The most representative IPC (International Patent Classifications) classes and subclasses were taken from the IPC codes of the 169 relevant patent applications. These IPC subclasses were identified to assist with future use in Industrial property monitoring. Table 5 shows the IPC classes and subclasses that appeared frequently in the patent applications on the production of lignocellulosic biodiesel.

The recovered IPC codes, classified into three main IPC classes: C10L-additives for biodiesel; C10G-mixtures of biodiesel and other fuels; and C12P-biochemical processes (fermentation processes or processes that use enzymes) for biodiesel production. Classes C12P-7 (oxygen-containing organic compounds) are the most frequent, followed by C10L-1 (liquid carbonaceous fuels) and C10G-1 (production of liquid hydrocarbon mixtures from oil shale, oil-sand, or non-melting solid carbonaceous or similar materials, e.g. wood). The most frequent subclasses related to the product (C12P-7/64, C12P-7/00, C10L-1/02, C10L-1/00, C10L-1/18, C10G-1/00, C10G-3/00), the type of biomass (C12P-7/10, C12P-19/02), or the type of conversion or reagents used (C12P-7/14, C10G-1/06, C10G-1/08, C12P-19/14), are important in the future monitoring of lignocellulosic biodiesel.

Figure 4 shows the global production in patent applications on lignocellulosic biodiesel production by year. The first's two patent applications were filed in

Table 5. IPC codes frequently used in patent applications on lignocellulosic biodiesel.

\begin{tabular}{|c|c|}
\hline IPC Class & Most common subclasses (frequency) and description \\
\hline C12P-7 (144) 89.44\% & $\begin{array}{l}\text { C12P-7/64 (50) Fats; fatty oils; ester-type waxes; higher fatty acids; } \\
\text { oxidized oils or fats. } \\
\text { C12P-7/10 (29) Substrate containing cellulosic material. } \\
\text { C12P-7/00 (18) Preparation of oxygen-containing organic compounds. } \\
\text { C12P-7/14 (10) Multiple stages of fermentation; multiple types of } \\
\text { microorganisms or reuse for microorganisms. }\end{array}$ \\
\hline C10L-1 (106) 65.83\% & $\begin{array}{l}\text { C10L-1/02 (39). Components consisting of carbon, hydrogen, and oxygen. } \\
\text { C10L-1/04 (20) Blends of hydrocarbons. } \\
\text { C10L-1/00 (15) Liquid carbonaceous fuels. } \\
\text { C10L-1/18 (11) Compounds containing oxygen. }\end{array}$ \\
\hline C10G-1 (79) 49.06\% & $\begin{array}{l}\text { C10G-1/00 (39) Production of liquid hydrocarbon mixtures } \\
\text { C10G-1/06 (13). Use of destructive hydrogenation. } \\
\text { C10G-1/08 (10) Use of moving catalysts. }\end{array}$ \\
\hline C12P-19 (65) 40.37\% & $\begin{array}{l}\text { C12P-19/14 (17) produced by the action of a carbohydrolase, e.g. } \\
\text { by alpha-amylase. } \\
\text { C12P-19/02 (16) Monosaccharides. }\end{array}$ \\
\hline C10G-3 (48) 29.81\% & $\begin{array}{l}\text { C10G-3/00 (38) Production of liquid hydrocarbon mixtures from } \\
\text { oxygen-containing organic materials, e.g. fatty oils, fatty acids. }\end{array}$ \\
\hline
\end{tabular}

Source: Based on data from Derwent innovation. 


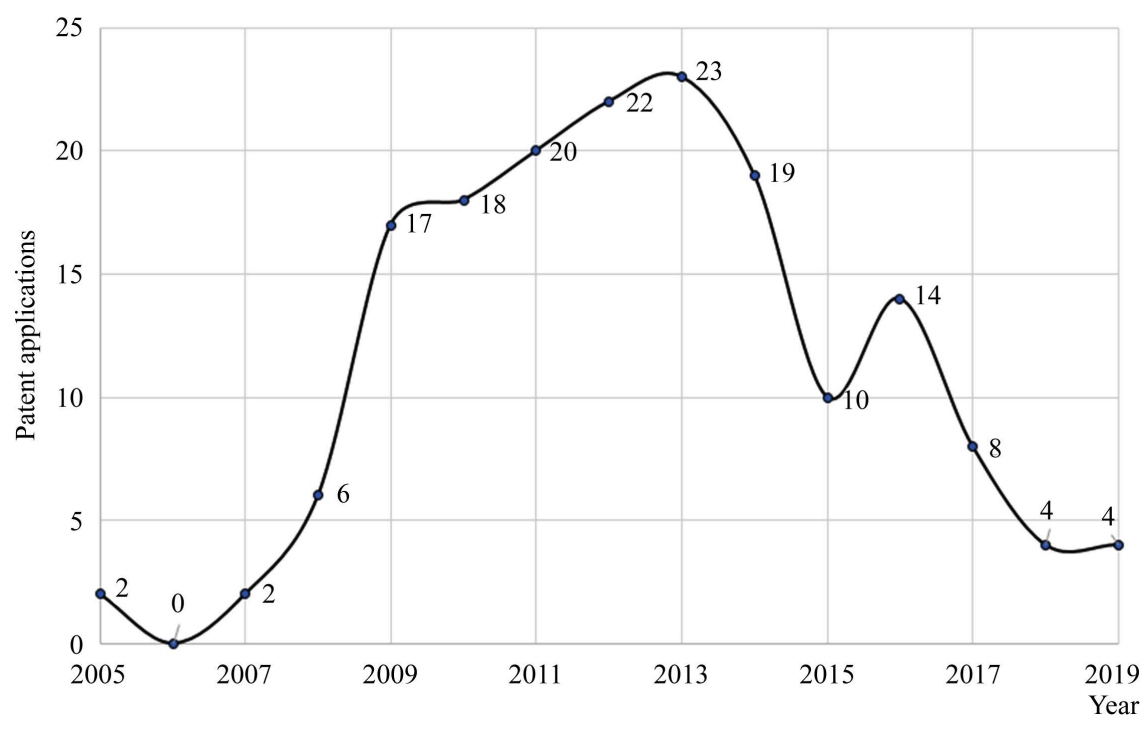

Figure 4. Annual production of patent applications on lignocellulosic biodiesel. Source: Based on data from Derwent Innovation.

2005, one in China (CN1624076-A) describes equipment using acid hydrolysis of lignocellulose biomass, the second was filed in USA (US2005177013-A1) and describes the conversion of agro-industrial waste into biofuels, such as crude oil, diesel, gasoline, and other fuels or oil products. There was an upward trend in patent applications until 2013, after which a decrease can be observed. An analysis of the global biofuel patent scenario shows that since the boom in the early 2000s, inventions in biofuel technologies have declined considerably and in many countries have gone into decline. Global trends indicate an uncertain future, especially for advanced biofuels [25]. It should be remembered that there is an 18-month secrecy period after a patent application is filed before it is indexed on databases. Therefore, the 2018 and 2019 data in Figure 4, do not necessarily indicate an actual reduction in patents.

\subsection{Patent Applications per Country}

Figure 5 shows the top ten countries in patent applications on lignocellulosic biodiesel production. USA and China together, account for $60 \%$ of the global patenting application. Sixty-nine out of 84 USA patent applications were filed by enterprises, while only six were filed by individuals and four by universities. Although China is highly productive on research (96 scientific articles), its patenting activity is relatively low (25 patent applications). Fifteen out of 25 Chinese patent applications were filed by Universities, six were by research institutes, and just one was an individual and one an enterprise. This limited patenting activity by enterprises could be due to the low biodiesel production levels in China because of a limited supply of raw materials [57]. There are over 50 biodiesel producer enterprises in China, most with a production capacity of fewer than 50.000 tons/year. Private biodiesel producer Chinese businesses account for over 95\% of overall biodiesel production. Almost all biodiesel in China comes from used oil, 


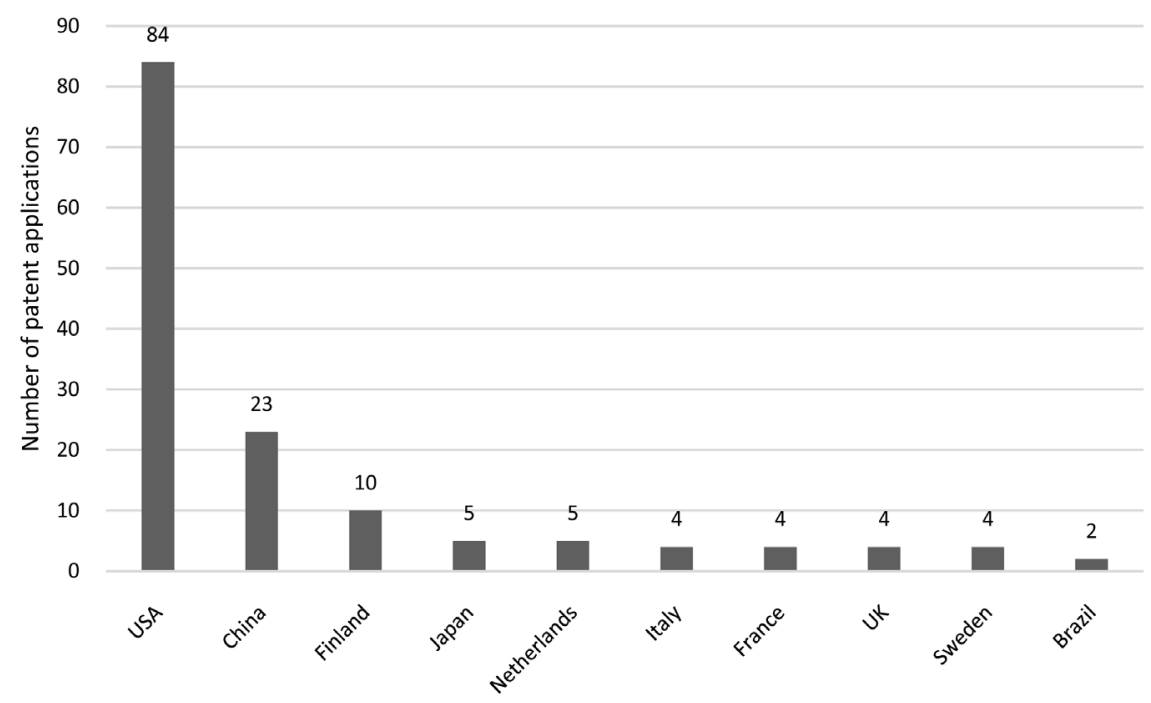

Figure 5. Patent applications per country. Source: Based on data from Derwent Innovation.

thanks to national political guidelines and incentives. India was the third top researcher, but no patent applications filed were identified.

\subsection{Patent Applications by Entity}

Enterprises are responsible for the majority of patent applications filed (108 patent applications, 67\%), followed by universities (15\%), research institutes (13\%) and individuals (5\%). Only 8 patent applications (15\%) were submitted by partnerships. Four of these partnerships were between enterprises (US2009064567-A1, WO2010063031-A2, WO2009059936-A2, WO2009152873-A1), three between an enterprise and a research institute (JP2014139283-A, WO2015193588-A1, WO2012030215-A1), and one between an enterprise and a university (US2010279372-A1). Table 6 shows the names and codes of entities with more than two patent applications, this table shows how diverse the global players are, in the development of lignocellulosic biodiesel innovations, ranging from enterprises on biotechnology field (Xyleco Inc.), oil and energy (BP Corp. North America Inc., Shell Oil Co., Eni S.P.A., Skandinavisk Kemiinformation), and biofuels (Kior Inc., Cool Planet Energy Systems Inc.). Shell is the enterprise with more patent applications filed (11), Six of these (US2012317873-A1, US2013152456-A1, WO2013066808-A1, US2013109896-A1, US2014165456-A1, WO2017004001-A1) describe hydrothermal and hydrocatalytic treatments for the conversion from lignocellulosic biomass to synthetic gasoline, diesel, jet-fuel, and other chemical compounds, with different variations, such as: use of catalytic hydrogenolysis with sulfur, molybdenum, and tungsten; a solid-separation filter, a hydrothermal digestion unit and a fluid circulation circuit; hydrogenation, hydrodeoxygenation, and liquid-liquid separation; catalytic hydrogenolysis using cobalt and nickel with aluminum support and high-pressure hydrocatalytic treatment. Two Shell patents applications (US2012152836-A1, US2016298292-A1) 
Table 6. Entities with more than two patent applications filed.

\begin{tabular}{ccc}
\hline Entity & Name of applicant and country of filing & applications \\
\hline Enterprise & SHELL OIL CO (USA) & 11 \\
Enterprise & NESTE OIL OYJ (Finland) & 6 \\
Enterprise & BP CORP NORTH AMERICA INC (USA) & 5 \\
Enterprise & SKANDINAVISK KEMIINFORMATION AB (Sweden) & 4 \\
Enterprise & KIOR INC (USA) & 4 \\
University & WUHAN UNI. OF SCIENCE \& TECHNOLOGY (China) & 3 \\
Enterprise & COOL PLANET ENERGY SYSTEMS INC (USA) & 3 \\
Institute & INST FRANCAIS DU PETROLE (France) & 3 \\
Enterprise & XYLECO INC (USA) & 3 \\
\hline
\end{tabular}

Source: Based on data from Derwent innovation. Period of analysis: 1996-2019.

describe the selective removal of compounds, with variations such as: removal of sulfur compounds and nitrogen compounds with hydrogenation and catalytic hydrogenolysis; selective removal of calcium, potassium, magnesium, and transition metals, followed by hydrothermal treatment. Finally, three Shell patent applications (US2013152457-A1, WO2013074437-A1, US2014096438-A1) use different techniques, including pressurization and digestion, catalytic hydropyrolysis, and biomass liquefaction.

Neste Oil has filed six patent applications (WO2010149859-A2, EP2468875-A1, EP2468877-A1, WO2012085340-A1, EP2735610-A1, WO2015086780-A1), these describe the use of lipid-producing microorganisms. They include genetically modified oleaginous bacteria to increase their lipid production; lipid-producing microorganisms in liquid-liquid and liquid-solid media; improvements in the enzyme stabilization system, filtration and separation methods, and tolerance to some inhibitors. BP Corp. North America has filed five patent applications (US2010146844-A1, WO2010129101-A1, US2010331560-A1, WO2013165962-A2, US2013130335-A1), aimed at producing synthetic gasoline, biodiesel, and chemicals. Major innovations include: depolymerization and extraction of pentoses; recycling of hydrolytic enzymes; removal of lignin; separation of pretreated biomass into separated fractions with high concentrations of lignin and sugars; and fermentation. The Swedish Skandanavisk Kemiinformation AB with four patent applications (SE201300378-A1, WO2013095204-A1, SE201000690-A1, SE201600009-A1), describe processes such as: lignin removal using solvents followed by catalytic depolymerization; hydrolysis and fermentation; catalytic pyrolysis and separation of cellulose from lignin by sodium hydroxide. Kior Inc. with four patent applications (WO2009118352-A1, US2012101318-A1, US2012204481-A1, US2012232299-A1) described bio-oil upgrading by inorganic catalysis and biocatalytic cracking, deoxygenation, hydrotreatment, fractioning of bio-oil and catalytic thermolysis of biomass.

Wuhan University of Science and Technology was the university with more 
patent applications filed (CN106755148-A, CN102660312-A, CN102154381-A), these documents described processes such as: fermentation controlled by carbon and nitrogen levels, oil extraction using solvent of organic and the use of enzymatic degradation. Two other Chinese universities have filed two patent applications: Huazhong University (CN103923948-A, CN101591684-A), and Zhejiang University (CN101255348-A, CN1624076-A). China is also the lider on patent applications filed by research institutes (6), followed by USA (5) and France (5). The Institut Français du Pétrole is the institute with more patent applications filed (FR2921385-A1, FR2957607-A1, WO2015193588-A1).

\section{Conclusions}

The Web of Science, Scopus, and Compendex databases were used to search scientific articles and the Derwent Innovation database was used to search for patent applications related to the production of biodiesel from lignocellulosic biomass. From this analysis the following conclusions were obtained:

1) Advances in research and technology in lignocellulosic biodiesel production have increased significantly since 2008, but in 2015 both began to decline sharply.

2) There were 300 scientific articles distributed in 97 journals, Bioresource technology (54 articles) was the most influential journal, followed by Biotechnology for Biofuels (18) and Green Chemistry (13).

3) Analysis of the author's keywords revealed hot topics on research. The main topic is the microbial production of lipids, with yeast being the most widely used microorganisms, in particular Cryptococcus, Trichosporon, and Rhodosporidium. The second topic of interest to researchers is acid and diluted acid pretreatment, and the third is pyrolysis. Moreover, sugarcane bagasse, corn and rice residues are the most investigated lignocellulosic biomasses.

4) This analysis also revealed top countries for research and innovation. China ranks first in total publications, followed by USA, and India. In the collaboration network, the China and USA had the strongest cooperative relationship (9 cooperative articles). USA ranks first in patent applications, followed by China and Finland.

5) The Dalian Institute of Chemical Physics was the world's leading research institute. (12 articles), and also has the most prolific author (Zongbao Zhao and collaborators, 6 articles). The South China University of Technology has the second top researcher (Min-Hua Zong and Hong Wu). Shell Oil Co. (11 applications) and Neste Oil Co. (6 applications) are the top patent applicants.

The analyses presented show global trends in research and innovation on lignocellulosic biodiesel production. The data provides a useful reference for biofuel manufacturers, academics, energy researchers, and political decision-makers. The results of this analysis are indicative; it is recommended to cross them with other analyses. The study could be complemented by an extensive analysis, provided by biofuel specialists. Future studies could continue to monitor collabora- 
tion networks, supplementing them with citations and impact indicators.

\section{Acknowledgements}

The authors gratefully thank the support of the following agencies: Coordenação de Aperfeiçoamento de Pessoal de Nível Superior-Brasil (CAPES) [Finance Code 001], and Empresa Brasileira de Pesquisa Agropecuária (EMBRAPA) [Grant number 15/2014 Ref. 16] for the financial support.

\section{Conflicts of Interest}

The authors declare no conflicts of interest regarding the publication of this paper.

\section{References}

[1] Aleixandre-Tudó, J., Castelló-Cogollos, L. and Aleixandre-Benavent, R. (2019) Renewable Energies: Worldwide Trends in Research, Funding and International Collaboration. Renewable Energy, 139, 268-278.

https://doi.org/10.1016/j.renene.2019.02.079

[2] Chuah, L.F., Klemeš, J.J., Yusup, S., Bokhari, A. and Akbar, M.M. (2017) A Review of Cleaner Intensification Technologies in Biodiesel Production Journal of Cleaner Production, 146, 181-193. https://doi.org/10.1016/j.jclepro.2016.05.017

[3] Balat, M. (2011) Potential Alternatives to Edible Oils for Biodiesel Production-A Review of Current Work. Energy Conversion Management, 52, 1479-1492. https://doi.org/10.1016/j.enconman.2010.10.011

[4] Janaun, J. and Ellis, N. (2010) Perspectives on Biodiesel as a Sustainable Fuel. Renewable Sustainable Energy Reviews, 14, 1312-1320.

https://doi.org/10.1016/j.rser.2009.12.011

[5] Azad, A.K. and Uddin, S.M. (2013) Performance Study of a Diesel Engine by First Generation Bio-Fuel Blends with Fossil Fuel: An Experimental Study. Journal of Renewable and Sustainable Energy, 5, Article ID: 013118. https://doi.org/10.1063/1.4790822

[6] Balan, V. (2014) Current Challenges in Commercially Producing Biofuels from Lignocellulosic Biomass ISRN Biotechnology, 2014, Article ID: 463074. https://doi.org/10.1155/2014/463074

[7] Wettstein, S.G., Martin, A.D., Gürbüz, E. and Dumesic, J.A. (2012) A Roadmap for Conversion of Lignocellulosic Biomass to Chemicals and Fuels. Current Opinion in Chemical Engineering, 1, 218-224. https://doi.org/10.1016/j.coche.2012.04.002

[8] Khot, M., Raut, G., Ghosh, D., Alarcon, M., Contreras, D. and Ravikumar, A. (2020) Lipid Recovery from Oleaginous Yeasts: Perspectives and Challenges for Industrial Applications. Fuel, 259, Article ID: 116292. https://doi.org/10.1016/j.fuel.2019.116292

[9] Kumar, D., Singha, A. and Korstad, J. (2017) Utilization of Lignocellulosic Biomass by Oleaginous Yeast and Bacteria for Production of Biodiesel and Renewable Diesel. Energy Reviews, 73, 654-671. https://doi.org/10.1016/j.rser.2017.01.022

[10] Yu, X., Zheng, Y., Dorgan, K.M. and Chen, S. (2011) Oil Production by Oleaginous Yeasts Using the Hydrolysate from Pretreatment of Wheat Straw with Dilute Sulfuric Acid. Bioresource Technology, 102, 6134-6140. 
https://doi.org/10.1016/j.biortech.2011.02.081

[11] Qin, L., Qian, H. and He, Y. (2017) Microbial Lipid Production from Enzymatic Hydrolysate of Pecan Nutshell Pretreated by Combined Pretreatment. Applied Biochemistry and Biotechnology, 183, 1336-1350.

https://doi.org/10.1007/s12010-017-2501-9

[12] Liu, W., Chen, W., Hou, Q., Zhang, J. and Wang, B. (2017) Surface Lignin Change Pertaining to the Integrated Process of Dilute Acid Pre-Extraction and Mechanical Refining of Poplar Wood Chips and Its Impact on Enzymatic Hydrolysis. Bioresource Technology, 228, 125-132. https://doi.org/10.1016/j.biortech.2016.12.063

[13] Ryosuke, Y., Yamauchi, A., Kashihara, T. and Ogino, H. (2017) Evaluation of Lipid Production from Xylose and Glucose/Xylose Mixed Sugar in Various Oleaginous Yeasts and Improvement of Lipid Production by UV Mutagenesis. Biochemical Engineering Journal, 128, 76-82. https://doi.org/10.1016/j.bej.2017.09.010

[14] Deeba, F., Pruthi, V. and Negi, Y.S. (2017) Fostering Triacylglycerol Accumulation in Novel Oleaginous Yeast Cryptococcus psychrotolerans IITRFD Utilizing Groundnut Shell for Improved Biodiesel Production. Bioresource Technology, 242, 113120. https://doi.org/10.1016/j.biortech.2017.04.001

[15] Garron, A., Al Maksoud, W., Larabi, C., Arquillière, P., Szeto, K.C., Walter, J.-J., et al. (2015) Direct Thermo-Catalytic Transformation of Pine Wood into Low Oxygenated Fuel: Influence of the Support. Catalysis Today, 255, 75-79.

https://doi.org/10.1016/j.cattod.2014.10.055

[16] de Rezende Pinho, A., de Almeida, M.B.B., Leal Mendes, F., Carlos Casavechia, L., Talmadge, M.S., Kinchin, C.M., et al. (2017) Fast Pyrolysis Oil from Pinewood Chips Co-Processing with Vacuum Gas Oil in an FCC Unit for Second Generation Fuel Production. Fuel, 188, 462-473. https://doi.org/10.1016/j.fuel.2016.10.032

[17] Treusch, K., Ritzberger, J., Schwaiger, N., Pucher, P.R. and Siebenhofer, M. (2017) Diesel Production from Lignocellulosic Feed: The bioCRACK Process. Royal Society Open Science, 4, Article ID: 171122. https://doi.org/10.1098/rsos.171122

[18] Grando, R.L., de Souza Antunes, A.M. and De Oliveira, C.B.J.F. (2016) Panorama do Biodiesel utilizando prospecção tecnológica. Ciência \& Tecnologia, 8, 55-72.

[19] Pritchard, J. (1969) Statistical Bibliography or Bibliometrics? Journal of Documentation, 25, 348-349.

[20] Fujino, A., Noronha, D.P. and Maricato, J.M. (2010) Bibliometric Analysis of Technological Production in Biodiesel: Contributions for ST\&I Policy. Perspectivas em Ciência da Informação, 15, 89-107. https://doi.org/10.1590/S1413-99362010000200007

[21] Zhai, C.A. and Ho, Y. (2018) Bibliometric Analysis of Distributed Control Publications. Measurement and Control, 51, 113-121. https://doi.org/10.1177\%2F0020294018768352

[22] Tolmac, D., Prulovic, S., Lambic, M., Radovanovic, L. and Tolmac, J. (2014) Global Trends on Production and Utilization of Biodiesel. Energy Sources, Part B: Economics, Planning, and Policy, 9, 130-139. https://doi.org/10.1080/15567241003773226

[23] Pham, L. (2019) Do All Clean Energy Stocks Respond Homogeneously to Oil Price? Energy Economics, 81, 355-379. https://doi.org/10.1016/j.eneco.2019.04.010

[24] Lamers, P. (2011) International Biodiesel Markets: Developments in Production and Trade. Ecofys C 3.1 National Renewable Energy Laboratory, UFOP, Berlin.

[25] Albers, S., Berklund, A. and Graff, G.D. (2016) The Rise and Fall of Innovation in 
Biofuels. Nature Biotechnology, 34, 814-822. https://doi.org/10.1038/nbt.3644

[26] Naylor, R. and Higginsb, M. (2017) The Political Economy of Biodiesel in an Era of Low Oil Prices. Renewable and Sustainable Energy Reviews, 77, 695-705. https://doi.org/10.1016/j.rser.2017.04.026

[27] Abraham, L. (2017) Clean Energy Investment Trends. Bloomberg, New Energy Finance, New Energy Finance Limited, London.

[28] Rodríguez, M.J. and Rodríguez, F.L. (2017) The Political Economy of Bioenergy in the United States: A Historical Perspective Based on Scenarios of Conflict and Convergence. Energy Research \& Social Science, 27, 141-150. https://doi.org/10.1016/j.erss.2017.03.002

[29] IEA (International Energy Agency) (2019) Transport Biofuels-Tracking Transport. Tracking Report IEA. International Energy Agency, Washington DC.

[30] Qiu, H.G., Sun, L.X., Huang, J.K. and Rozelle, S. (2012) Liquid Biofuels in China: Current Status, Government Policies, and Future Opportunities and Challenges. Renewable and Sustainable Energy Reviews, 16, 3095-3104. https://doi.org/10.1016/j.rser.2012.02.036

[31] Zhao, X.G. and Liu, P. (2014) Focus on Bioenergy Industry Development and Energy Security in China. Renewable Sustainable Energy Reviews, 32, 302-312. https://doi.org/10.1016/j.rser.2014.01.011

[32] Perumal Saravanan, A., Mathimani, T., Deviram, G., Rajendran, K. and Pugazhendhi, A. (2018) Biofuel Policy in India: A Review of Policy Barriers in Sustainable Marketing of Biofuel. Journal of Cleaner Production, 193, 734-747. https://doi.org/10.1016/j.jclepro.2018.05.033

[33] Smith, R. (2018) Three Countries Are Leading the Renewable Energy Revolution. World Economic Forum.

https://www.weforum.org/agenda/2018/02/countries-behind-global-renewable-ener gy-growth/

[34] Partzsch, L. (2017) Biofuel Research: Perceptions of Power and Transition. Energy, Sustainability and Society, 7, Article No. 14. https://doi.org/10.1186/s13705-017-0116-1

[35] Hoekman, J. and Frenken, F. (2009) The Geography of Collaborative Knowledge Production in Europe. The Annals of Regional Science, 43, 721-738. https://doi.org/10.1007/s00168-008-0252-9

[36] Montobbio, F. and Sterzi, V. (2013) The Globalization of Technology in Emerging Markets: A Gravity Model on the Determinants of International Patent Collaborations. World Development, 44, 281-299. https://doi.org/10.1016/j.worlddev.2012.11.017

[37] IEA (International Energy Agency) (2017) Tracking Clean Energy Progress 2017. Technical Report, International Energy Agency, Washington DC.

[38] Milani, S. (2019) Who Innovates with Whom and Why? Evidence from International Collaboration in Energy Patenting. Economics of Innovation and NeW Technology, 29, 369-393. https://doi.org/10.1080/10438599.2019.1629531

[39] Zhang, M., Gao, Z., Zheng, T., Ma, Y., Wang, Q., Gao, M. and Sun, X. (2018) A Bibliometric Analysis of Biodiesel Research during 1991-2015. Journal of Mater Cycles Waste Management, 20, 10-18. https://doi.org/10.1007/s10163-016-0575-Z

[40] Chen, X., Li, Z., Zhang, X., Hu, F., Ryu, D.Y. and Bao, J. (2009) Screening of Oleaginous Yeast Strains Tolerant to Lignocellulose Degradation Compounds. Applied Biochemistry and Biotechnology, 159, Article No. 591. 
https://doi.org/10.1007/s12010-008-8491-x

[41] Wells Jr., T., Wei, Z. and Ragauskas, A. (2010) Bioconversion of Lignocellulosic Pretreatment Effluent via Oleaginous Rhodococcus opacus DSM 1069. Biomass and Bioenergy, 72, 200-205. https://doi.org/10.1016/j.biombioe.2014.11.004

[42] Reis, C., Zhang, J. and Hu, B. (2014) Lipid Accumulation by Pelletized Culture of Mucor circinelloides on Corn Stover Hydrolysate. Applied Biochemistry and Biotechnology, 174, 411-423. https://doi.org/10.1007/s12010-014-1112-y

[43] Wei, Z., Zeng, G., Huang, F., Kosa, M., Sun, Q. and Meng, X. (2015) Microbial Lipid Production by Oleaginous Rhodococci Cultured in Lignocellulosic Autohydrolysates. Applied Microbiology and Biotechnology, 99, 7369-7377. https://doi.org/10.1007/s00253-015-6752-5

[44] Xue, Y.P., Jin, M., Orjuela, A., Slininger, P.J., Dien, B.S., Dale, B.E., et al. (2015) Microbial Lipid Production from AFEX ${ }^{\mathrm{Tm}}$ Pretreated Corn Stover. RSC Advances, 5, 28725-28734. https://doi.org/10.1039/C5RA01134E

[45] Fei, Q., O’Brien, M., Nelson, R., Chen, X., Lowell, A. and Dowe, N. (2016) Enhanced Lipid Production by Rhodosporidium toruloides Using Different Fed-Batch Feeding Strategies with Lignocellulosic Hydrolysate as the Sole Carbon Source. Biotechnology for Biofuels, 9, Article No. 130.

[46] Ke, J., Laskar, D.D. and Chen, S. (2013) Tetramethylammonium Hydroxide (TMAH) Thermochemolysis for Probing in Situ Softwood Lignin Modification in Each Gut Segment of the Termite. Journal of Agricultural and Food Chemistry, 6, 1299-1308. https://doi.org/10.1021/jf3048548

[47] Ahmad, S., Alatefi, M., Alkahtani, M., Anwar, S., Sharaf, M. and Abdollahian, M. (2019) Bibliometric Analysis for process Capability Research. Quality Technology \& Quantitative Management, 16, 459-477. https://doi.org/10.1080/16843703.2018.1464426

[48] Steen, E.J., Kang, Y., Bokinsky, G., Hu, Z., Schirmer, A., McClure, A., et al. (2010) Microbial Production of Fatty-Acid-Derived Fuels and Chemicals from Plant Biomass. Nature, 463, 559-562. https://doi.org/10.1038/nature08721

[49] Rude, M.A. and Schirmer, A. (2009) New Microbial Fuels: A Biotech Perspective. Current Opinion in Microbiology, 12, 274-281.

https://doi.org/10.1016/j.mib.2009.04.004

[50] KeaslingLab (2020) Biofuels. https://keaslinglab.lbl.gov/application-areas/

[51] Onda, A., Ochia, T. and Yanagisawaa, K. (2008) Selective Hydrolysis of Cellulose Into glucose over Solid Acid Catalysts. Green Chemistry, 10, 1033-1037. https://doi.org/10.1039/B808471H

[52] Onda, A., Ochi, T. and Yanagisawa, K. (2009) Hydrolysis of Cellulose Selectively into Glucose over Sulfonated Activated-Carbon Catalyst under Hydrothermal Conditions. Topics in Catalysis, 52, 801-807. https://doi.org/10.1007/s11244-009-9237-x

[53] Li, Y., Zhao, Z. and Bai, F. (2007) High-Density Cultivation of Oleaginous Yeast Rhodosporidium toruloides Y4 in Fed-Batch Culture. Enzyme and Microbial Technology, 41, 312-317. https://doi.org/10.1016/j.enzmictec.2007.02.008

[54] Hu, C., Zhao, Z., Zhao, J., Wu, S. and Zhao, Z.K. (2009) Effects of Biomass Hydrolysis By-Products on Oleaginous Yeast Rhodosporidium toruloides. Bioresource Technology, 100, 4843-4847. https://doi.org/10.1016/j.biortech.2009.04.041

[55] Zhao, X., Kong, X., Hua, Y., Feng, B. and Zhao, Z. (2008) Medium Optimization for Lipid Production through Co-Fermentation of Glucose and Xylose by the Oleagin- 
ous Yeast Lipomyces starkeyi. European Journal of Lipid Science and Technology, 110, 405-412. https://doi.org/10.1002/ejlt.200700224

[56] Nicolaisen, J. (2009) Bibliometrics and Citation Analysis: From the Science Citation Index to Cybermetrics. Journal of the American Society for Information Science and Technology, 61, 205-207. https://doi.org/10.1002/asi.21181

[57] REN21 Community (2019) Renewables 2019 Global Status report. Renewables Now. https://www.ren21.net/wp-content/uploads/2019/05/gsr 2019 full report en.pdf

[58] Harris, P., Welner, D., McFarland, K.C., Re, E., Navarro Poulsen, J.-C., Brown, K., et al. (2010) Stimulation of Lignocellulosic Biomass Hydrolysis by Proteins of Glycoside Hydrolase Family 61: Structure and Function of a Large, Enigmatic Family. Biochemistry, 49, 3305-3316. https://doi.org/10.1021/bi100009p

[59] Kalscheuer, R., Stölting, T. and Steinbuchel, A. (2006) Microdiesel: Escherichia coli Engineered for Fuel Production. Microbiology Society, 152, 2529-2536. https://doi.org/10.1099/mic.0.29028-0

[60] Wildschut, J., Mahfud, F., Venderbosch, R. and Heeres, H. (2009) Hydrotreatment of Fast Pyrolysis Oil Using Heterogeneous Noble-Metal Catalysts. Catalysts Industrial \& Engineering Chemistry Research, 48, 10324-10334.

https://doi.org/10.1021/ie9006003

[61] Aho, A., Kumar, N., Eränen, K., Salmi, T., Hupa, M. and Murzin, D.Y. (2008) Catalytic Pyrolysis of Woody Biomass in a Fluidized Bed Reactor: Influence of the Zeolite Structure. Fuel, 87, 2493-2501. https://doi.org/10.1016/j.fuel.2008.02.015

[62] Chen, S., Dorgan, K. and Zheng, Y. (2011) Oil Production by Oleaginous Yeasts Using the Hydrolysate from Pretreatment of Wheat Straw with Dilute Sulfuric Acid. Bioresource Technology, 102, 6134-6140. https://doi.org/10.1016/j.biortech.2011.02.081

[63] Wu, H., Zong, M.H., Huang, C. and Liu, Q.P. (2009) Microbial Oil Production from Rice Straw Hydrolysate by Trichosporon fermentans. Bioresource Technology, 100, 4535-4538. https://doi.org/10.1016/j.biortech.2009.04.022

[64] Corma, A., de la Torre, C., Renz, M. and Villandier, N. (2011) Production of HighQuality Diesel from Biomass Waste Products. Angewandte Chemie International Edition, 50, 2375-2378. https://doi.org/10.1002/anie.201007508 